\title{
BMJ Global Health How did rapid scale-up of HIV services impact on workplace and interpersonal trust in Zambian primary health centres: a case-based health systems analysis
}

\author{
Stephanie M Topp, ${ }^{1,2}$ Julien M Chipukuma ${ }^{3}$
}

To cite: Topp SM, Chipukuma JM. How did rapid scale-up of HIV services impact on workplace and interpersonal trust in Zambian primary health centres: a case-based health systems analysis. BMJ Global Health 2016;1:e000179. doi:10.1136/bmjgh-2016000179

Received 5 September 2016 Revised 7 November 2016 Accepted 24 November 2016

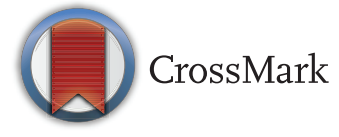

${ }^{1}$ College of Public Health, Medical and Veterinary Sciences, James Cook University, Townsville, Queensland, Australia ${ }^{2}$ Nossal Institute for Global Health, University of Melbourne, Melbourne, Victoria, Australia ${ }^{3}$ Lusaka University, Lusaka, Zambia

\section{Correspondence to} Dr Stephanie M Topp; globalstopp@gmail.com

\section{ABSTRACT}

Background: In sub-Saharan Africa, large amounts of funding continue to be directed towards HIV-specific care and treatment, often with claims of 'health system strengthening' effect. Such claims rarely account for the impact on human relationships and decisions that are core to functional health systems. This research examined how establishment of externally funded HIV services influenced trusting relationships in Zambian health centres.

Methods: An in-depth, multicase study included four health centres selected for urban, peri-urban and rural characteristics. Case data included healthcare worker (HCW) interviews (60); patient interviews (180); direct observation of facility operations (2 weeks/ centre) and key informant interviews (14) which were recorded and transcribed verbatim. Thematic analysis adopted inductive and deductive coding guided by a framework incorporating concepts of workplace trust, patient-provider trust, intrinsic and extrinsic motivation.

Results: HIV service scale-up impacted trust in positive and negative ways. Investment in HIV-specific infrastructure, supplies and quality assurance mechanisms strengthened workplace trust, HCW motivation and patient-provider trust in HIV departments in the short-term. In the health centres more broadly and over time, however, nongovernmental organisation-led investment and support of HIV departments reinforced HCW's perceptions of the government as uninterested or unable to provide a quality work environment. Exacerbating existing perceptions of systemic workplace inequity and nepotism, uneven distribution of personal and professional opportunities related to HIV service establishment contributed to interdepartmental antagonism and reinforced workplace practices designed to protect individual HCW's interests. Conclusions: Findings illustrate long-term negative effects of the vertical HIV resourcing and support structures which failed to address and sometimes exacerbated HCW (dis)trust with their own government and supervisors. The short-term and long-term effects of weakened workplace trust on HCWs' motivation and performance signal the importance of understanding how such relationships

\section{Key questions}

What is already known about this topic?

- Trusting relationships are a core component of functional health services and health systems.

- In Western countries, theoretical and empirical research has examined the way workplace and patient-provider trust influence the efficiency and effectiveness of health service delivery. However, little is known about the impact on trust of investment in large, externally funded service 'scale-up' programmes in low-income and middle-income settings.

- In Zambia - and many other sub-Saharan African countries-the scale and speed with which HIV services were introduced in the mid-to-late 2000s is likely to have had some effect on workplace and patient-provider trusting relationships.

- Understanding what sort of impact and with what implications for service efficiency and efficacy is an important component of improving the design of future global (and national) health service reforms.

What are the new findings?

- The study demonstrates some short-term and service-specific positive impacts on trust in Zambian health centre, but also longer term and more far reaching negative impacts on workplace and provider trust due to the speed and the (largely vertical) nature of the investment in HIV services.

- The study provides empirical evidence to demonstrate how selective investment in HIV services at the primary level, without consideration of the generally integrated nature of front line service delivery impacted on various trusting relationships, with implications for health worker motivation, common work practices and patient-provider trust.

play a role in generating virtuous or perverse cycles of actor interactions, with implications for service outcomes. 


\section{Key questions}

\section{Recommendations for policy}

- International and national-level health policymakers and programmers must recognise and engage with the human, relational features of health systems when planning major service interventions or reforms.

- Not to do so risks losing opportunities to leverage major investments in specific diseases towards stronger and more resilient health systems that respond efficiently and effectively to existing and emerging health needs.

\section{INTRODUCTION}

The international response to HIV saw global funding for the disease increase from US\$300 million in 1996 to an estimated US $\$ 20.2$ billion in $2014 .{ }^{1}{ }^{2}$ The largest proportion of this funding was directed to a comparatively small number of countries such as Zambia in sub-Saharan Africa, where HIV/AIDS constitutes a major health, social and economic threat. ${ }^{3}$ The necessity and urgency of responding to the HIV epidemic has never been in question. However, the exceptional levels of funding and the scale and speed of HIV-specific programmes did spur debate regarding the impact of disease-specific programmes on recipient countries' health systems. ${ }^{3-11}$

One question central to the debate over the value of disease-specific programming is whether disease-specific funding has 'system strengthening' effects ${ }^{12-16}$ and since 2010 a small but growing body of empiric, evaluative research has emerged. Findings have been mixed. Some have demonstrated that the resources and momentum generated by HIV-specific funding-in particular from the Global Fund to Fight AIDS Tuberculosis and Malaria (GFATM) and the Presidents Emergency Plan for AIDS Relieve (PEPFAR) - had positive spill over effects for the general system, ${ }^{17}$ maternal health coverage,${ }^{18}{ }^{19}$ human resourcing ${ }^{20}{ }^{21}$ procurement, training, health information and laboratory systems. ${ }^{22}$ Others, however, have shown that targeted HIV investment simultaneously 'crowded out' non-HIV care, ${ }^{23}{ }^{24}$ served as a distraction to policy and front line decision makers ${ }^{25}$ created duplications and inefficiencies including through establishment of parallel health information and laboratory systems ${ }^{26}$ and contributed to internal brain drain. ${ }^{14} 2728$ Two notable features of this body of the literature are the largely macro or national-level evaluative framework and the thematic focus on the most tangible aspects of health system 'hardware' including as human resources, supply chain and laboratory capacity and service outputs.

Largely absent, to date, are empirical evaluations of the impact of HIV investment on meso-level and microlevel health systems (eg, district offices and health centres) or the impact on so-called health system 'software'; the norms, values and dynamic relationships that underpin health service performance. Some notable exceptions do exist ${ }^{29-33}$ and provide critical insights. Yet with increasing recognition by policymakers and planners that health systems are 'social systems' ${ }^{34}$ the limited scope and depth of evaluative work in this domain remains concerning.

The study reported here formed part of a larger research project ${ }^{i}$ that aimed to address the evidence gap vis-à-vis the influence of HIV service scale-up on health system software via a series of case studies in Zambian primary health centres (PHCs). An initial objective of the larger study was to produce theoretically informed insights relating to the mechanisms driving health centre performance. The project first demonstrated the critical role of trust and accountability in determining primary-level service quality and responsiveness in the Zambian setting. ${ }^{35}{ }^{36}$ Extending this focus, the study presented here subsequently examined whether and how the scale-up of HIV services influenced the production of trust within Zambian PHCs and with what implications for sustained service quality and responsiveness.

\section{Conceptual framework}

Following Hall et al, we define trust as the 'optimistic acceptance of a vulnerable situation in which the trustor believes the trustee will care for their interests ${ }^{, 37}$ and our understanding of trust and its production in health centres draws specifically on the concepts of workplace and interpersonal trust outlined in Gilson et al. ${ }^{38}$ Following a scoping review of the literature, previous work explored the nature of these concepts-among other approaches to examining trust-and qualitatively validated their applicability to the Zambian setting, ${ }^{35}$ we refer readers to this previous work for a more in-depth examination of trust from a theoretical perspective. For the purpose of this study, the concepts of workplace and interpersonal trust form part of the framework outlined in figure 1, which suggests that trust in the health sector is the product of interactions between workplace and patient-provider trust, respectively. Workplace trust is defined by healthcare providers' trust in their employer, supervisors and colleagues, which together influence orientation and responsiveness to patients. Providers' orientation and responsiveness, in turn, form a key input to patient-provider trust, which is jointly shaped by interpersonal trust as well as patients' broader trust in the institutions that regulate health workers' behaviour. ${ }^{39-43}$

\section{METHODS}

\section{Study setting}

This study was set in Zambian PHCs providing HIV and a variety of routine outpatient and maternal and child

${ }^{\mathrm{i} A}$ project entitled: 'Mechanisms of effect: a health systems analysis of the impact of introducing treatment services for human immunodeficiency virus (HIV) into four public primary health centres in Zambia'. 


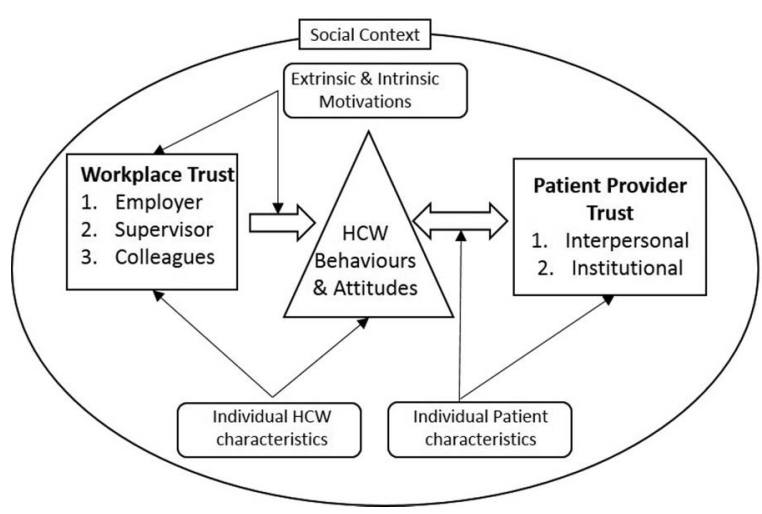

Figure 1 Conceptual Framework (adapted from Okello and Gilson). ${ }^{57}$

health services. PHCs make up the majority $(79 \%)$ of Zambia's health facilities, with $\sim 29 \%$ of these located in urban areas. Nominally, urban PHCs serve a catchment of 30000 to 50000 people and rural PHCs serve a population of up to $10000^{44}$ although actual catchment populations are often larger. PHCs along with first level hospitals are administrated by District Health Offices, while Provincial Health Offices and central Ministry of Health $(\mathrm{MOH})$ offices manage secondary and tertiary hospital operations, respectively. The typical administrative structure for PHCs includes an overall health centre manager ('in-charge') deputised by various departmental managers responsible for outpatient, tuberculosis (TB), maternal and child health (MCH) and 'antiretroviral therapy (ART) clinic' services. Following the 2003 announcement of a policy promising free and universal access to ART and subsequent financial support from GFATM and PEPFAR (among others), Zambia rapidly introduced ART clinics at the PHC level with the assistance of various non-government implementing partners'. At the time of writing, Zambia had one of the world's largest HIV-treatment programmes with more than $600000 \mathrm{HIV}$-infected individuals enrolled in care.

\section{Study design}

The overall aim of this study was to examine whether and how the scale-up of HIV services impacted on workplace and patient-provider trust in four Zambian PHCs.

The methods for the larger project of which this study formed one part have been described in detail elsewhere. ${ }^{36}$ Of relevance to this study a multicase design was adopted ${ }^{45}$ with four PHCs each representing a case unit. Health centres were purposively chosen from two districts within the same province and selection was based on established ( $>36$ months) HIV care and treatment service and a catchment population based on either a large urban facility (>100 000 population), small urban facility $(40000-70000)$, peri-urban facility $(<40000)$ or rural facility $(<30000)$, respectively. A list of all facilities that fitted the criteria was initially developed and case selection conducted in collaboration with
District Medical Officers and local colleagues simultaneously accounting for access and logistical issues. Final selection was subject to the informed consent of the manager of each centre.

Data were collected between June and December 2011. Data collection methods included document review, in-depth interviews with a proportionate sample of healthcare workers from all health centre departments $(n=60)$; structured observations and semistructured interviews (conducted postconsultation/observation) with a quasi-random sample of patients $(n=180)$; review of health centre paper-based registers and direct unstructured observation of facility operations (2-3 weeks per site). Structured observations focused on recording explicit activities (eg, medical history, physical examination and blood draw) and the type of information exchanged between health workers and patients during routine screening visits in the outpatient, MCH, TB and HIV departments. Unstructured observations were guided by a note-taking tool developed from the conceptual framework and included notes on informal discussions and interactions. Key informant interviews with government and non-government officials $(\mathrm{n}=14)$ with specific knowledge or experience in front line supervision were additionally conducted.

Question guides were designed to elicit detailed descriptions of interactions among and between staff and patients to provide insight into whether and why the introduction and scale-up of HIV service delivery influenced trust in health centre relationships. Prior experience of conducting interviews in Zambian health centres ${ }^{46} 47$ demonstrated that when asked direct questions about interpersonal interactions, patients and providers often provided undifferentiated and affirming descriptions despite observations suggesting more complex of relationships. Owing to this risk of social desirability bias, question guides did not ask directly about trust. ${ }^{48}$ Rather, following the conceptual framework outlined above, issues explored under the rubric of workplace trust included contrasting health worker expectations and perceptions of support from their employer or quasi-employer (eg, non-governmental organisation (NGO) implementing partner); expectations and perceptions of line managers and collegiality -including willingness to rely or depend on other health workers under different conditions. Issues explored under the rubric of interpersonal trust included HIV and non-HIV patients' expressions of faith in health workers' service skills and service orientation; confidence that health workers in different departments were adequately skilled and hopes, expectations and experiences of receiving timely and respectful care. Responses were triangulated with direct observations to provide a better understanding of the way HIV services and associated support activities influenced different aspects of workplace and patient-provider trust.

The primary investigator conducted all the health worker interviews in English. Patient interviews were 
conducted by one of two trained research assistants in the participants' choice of English, Nyanja or Bemba. All interviews were conducted in private rooms in the health centres. Written informed consent was obtained from all participants (patients, providers and key informants) for any observations or interviews. The study received ethical clearance from the Human Research Ethics Committee of the Nossal Institute, University of Melbourne, and the University of Zambia Biomedical Research Ethics Committee.

Analysis was carried out in three phases. Phase I was conducted concurrently with data collection, as collated notes and summaries of evidence were generated for each health centre and transcribed interviews imported into NVivo V.8 QSR for electronic coding. In phase II, data were organised to produce a case description for each health centre. Qualitative and observational data were synthesised and compared in order to develop as comprehensive a picture as possible of the impact of HIV service scale-up on trust at each site with preliminary case descriptions disseminated to the health-centre managers and District Medical Officers to garner feedback. Phase III focused on cross case comparisons using deductive and inductive analysis. Initial deductive analysis was guided by codes developed from the conceptual framework including: system hardware (financing, human resourcing, drug supplies); system software (leadership, workplace norms, patient expectations); workplace trust (employer, supervisor, colleagues) and patient-provider trust (interpersonal, institutional). Coded text and its (anonymised) source were collated in a word document and printed to enable synthesis of major findings. Theoretically, generated codes were supplemented with inductive codes, and commonalities identified across the four cases.

\section{FINDINGS}

We present findings in two sections. First, we briefly outline the key characteristics of the process of HIV service scale-up in the four study sites. Second, we examine the impact of those processes on workplace trust (incorporating trust in employer, supervisor and colleagues) and patient-provider trust (incorporating interpersonal trust and institutional trust). We use the terms 'health worker' and 'provider' interchangeably, but distinguish between 'professionals' referring to those with a clinical qualification recognised by the $\mathrm{MOH}$ and on payroll, versus 'lay' health workers referring to those working in voluntary or stipendiary positions supported by non-government organisations.

\section{CHARACTERISTICS OF HIV SCALE-UP IN FOUR STUDY SITES}

Table 1 outlines the demographic profile of the two districts in which study sites were located, and table 2 summarises the operational characteristics of the study health centres and major features of the 'establishment phase' (2006-2009) and 'transition and scale-up phase' (2010-2011) of Zambian HIV service scale-up, respectively, on those health centres. During the establishment phase, HIV services were introduced initially as stand-alone 'ART clinics' between 2006 and 2009. ART clinics were located within existing health centre grounds, but most material and technical support were delivered by PEPFAR-funded NGO implementing partners. Key components of this establishment phase thus included provision of training; substantial investment in new or renovated infrastructure; clinical training for select staff; recruitment and financing of a new cadre of lay health workers ('HIV peer educators') to carry out essential non-clinical duties in the ART clinic; establishment of an HIV-specific electronic medical record system; a HIV-specific supply chain and the provision of NGO support for quality assurance. In order to overcome chronic staff shortages in the three urban health centres, 'overtime' payments were also provided to existing $\mathrm{MOH}$ professionals to work extra shifts in the new ART clinics. In-service training was paid for and delivered by NGO implementing partners but accredited by $\mathrm{MOH}$. Critically, early involvement and oversight of these activities by District Health Management Teams were limited.

The scale-up and transition phase saw several shifts in the nature of HIV service support. In three facilities, in-service training opportunities were extended to all professional staff. However, changes in PEPFAR policy resulted in cuts to donor-funded salary-support for HIV peer educators. Similar policy shifts saw the removal of the donor-funded overtime payments for professional staff and, in an effort to transition responsibility for oversight of ART clinics away from NGO implementing partners and towards District and Provincial offices, this phase saw a winding down of the NGO-supported quality assurance programmes. By late 2011, for example, quality assurance visits to all four sites were largely ad hoc, compared to the nearly weekly visits that had taken place between 2006 and 2010.

Table 1 Demographic and socioeconomic characteristics of districts where study sites were located ${ }^{\star}$

\begin{tabular}{|c|c|c|}
\hline & Lusaka & Chongwe \\
\hline Total households & 368364 & 37573 \\
\hline Total population & 1742979 & 187969 \\
\hline $\begin{array}{l}\text { Average annual rate } \\
\text { Population growth 2000- } \\
2010\end{array}$ & $4.9 \%$ & $3.2 \%$ \\
\hline Male population (\%) & $\begin{array}{l}852588 \\
(49 \%)\end{array}$ & $\begin{array}{l}93934 \\
(50 \%)\end{array}$ \\
\hline Population density & 4841.6 & 21.7 \\
\hline District welfare (FOD)† rank & $5 / 74$ & $13 / 74$ \\
\hline
\end{tabular}

*Sources: 2010 Census of Population and Housing; ${ }^{49}$ Comparison of Welfare Status of Districts in Zambia, ZIPAR, 2014. ${ }^{50}$ †FOD, First Order Dominance; ranking based on relative deprivation in relation to access to: sanitation, employment, housing, electricity and education. 
Table 2 Study sites: operational characteristics and common features of HIV service scale up

\begin{tabular}{|c|c|c|c|c|}
\hline Demographic features & Health centre 1 & Health centre 2 & Health centre 3 & Health centre 4 \\
\hline Designation & Urban & Rural & Urban & Peri-Urban \\
\hline Official catchment population* & 62579 & 15000 & 101972 & 43850 \\
\hline $\begin{array}{l}\text { Common features of ART clinic } \\
\text { establishment (c. 2005-2008) }\end{array}$ & \multicolumn{4}{|c|}{$\begin{array}{l}\text { New stand-alone building for ART clinic in three sites }(\mathrm{HC} 1, \mathrm{HC} 3, \mathrm{HC} 4) \\
\text { Externally funded/supported supply chain and laboratory services } \\
\text { Recruitment and training of adult and paediatric peer educators/establishment of peer } \\
\text { support groups } \\
\text { NGO funded/run in-service training for select professional staff } \\
\text { Donor-funded 'overtime' payments for professional staff (HC1, HC3, HC4) } \\
\text { NGO-supported quality assurance systems } \\
\text { Electronic medical records in three sites (HC1, HC3, HC4); ART specific stationary at all } \\
\text { sites }\end{array}$} \\
\hline $\begin{array}{l}\text { Common features of ART clinic } \\
\text { scale-up and transition (c. } \\
\text { 2009-2011) }\end{array}$ & \multicolumn{4}{|c|}{$\begin{array}{l}\text { Extension of HIV in-service training to all professional staff } \\
\text { Removal of donor-funded overtime payments }(\mathrm{HC} 1, \mathrm{HC}, \mathrm{HC} 4) \\
\text { Formal inclusion of ART clinic services in routine duties of all professional staff } \\
\text { Scale-back in NGO support for lay personnel (including peer educators and defaulter } \\
\text { tracing) } \\
\text { Scale-back in NGO support for quality assurance programmes } \\
\text { Externally funded, but MOH-managed HIV supply chain }\end{array}$} \\
\hline
\end{tabular}

${ }^{*}$ At the time of study.

${ }^{\dagger}$ Includes paid or stipendiary lay staff with formal terms of reference; does not include ad hoc voluntary lay staff.

ART, antiretroviral therapy clinic; EH, environmental health department; IPD, inpatient department; Labour, labour ward; $\mathrm{MCH}$, maternal and child health department; NGO, non-governmental organisation; OPD, outpatient department; TB, tuberculosis treatment department.

\section{THE IMPACT OF HIV SERVICE SCALE-UP ON WORKPLACE TRUST}

\section{Trust in employer (or quasi-employer)}

The establishment phase of HIV service scale-up was characterised by a substantial investment of material and technical support in the ART clinics delivered almost exclusively by an NGO implementing partner. The reliability of ART supply chain combined with timely nature of over-time and stipendiary payments to professional and lay staff, respectively, contributed to health workers' trust in these implementing partners as a reliable 'quasi-employer' capable of supporting their professional workplace needs.

Drugs were always available [in the ART clinic], we were never short of ARVs. Clinical Officer, HC3

Things were different in the ART clinic. You didn't go short and if equipment broke it would be replaced. Nurse, HC1.

In contrast, health workers expressed doubt in the commitment and capacity of their formal employerthe government-to resource and govern health services. Health worker respondents from all clinics made comparisons between the ART clinic and other health centre departments contrasting the (at least initially) well-resourced and externally supported HIV services with the perpetually under-resourced outpatient (and to a lesser extent $\mathrm{MCH}$ ) departments.

There is nothing from the government. No equipment, no drugs. Not even bread and sugar for our tea. Midwife, HC1.

Such comparisons were frequently accompanied by statements demonstrating high levels of antipathy indicative of mistrust in the government's intent, such as this nurse who stated bluntly:

'I feel [the government] does not care about us'. Nurse, HC2.

The shifts in policy regarding HIV-specific salary support in the scale-up and transition phase had further negative effects on health workers' trust in their formal (government) and quasi (NGO implementing partner) employers. Professional staff expressed resentment and framed the 'new' requirement to deliver HIV services as part of routine duties as 'unfair' since it was 'additional' and 'unpaid' work.

OK, those days when I just started in 2006, they used to pay us but the [NGO] people they just stopped paying us. It was unfair. ART Nurse, HC3 
Many simultaneously described a sense of being taken for granted by the government and NGO agencies ${ }^{\mathrm{ii}}$ and health centre managers linked these resentments to the emergence, in the ART clinic, of unproductive work patterns long established in other departments. These notably included absenteeism, shorter consultation times, skipping of essential tasks and weak data management. ${ }^{\text {iii }}$

Removal of stipendiary support for lay workers (including HIV peer educators and data-entry and filing staff) resulted in many from this cadre cutting back hours in the ART clinic or leaving the facility entirely. This reduction in staff capacity led to service bottlenecks (observed in all four ART clinics at the time of study). Indicative of weak trust that the government would incorporate their position into a formal or 'establishment' role, but unwilling to abandon their post altogether, some lay health workers did stay in the ART clinics but engaged in informal payment schemes to compensate for lost income:

It is automatic that [the lay health workers] are charging some patients; that's why [these workers] come now since they are not being [paid anymore]. Registry Clerk, HC1.

The implications of these schemes and reduced support for lay health workers are discussed further below in the 'Interpersonal trust' section.

Providers' weakened trust in formal (government) and quasi-(non-government) employers during the scale-up and transition phase impacted on motivation and performance. Frustration and resentment related to removal of overtime payments and perceptions of increased workload led some professional health workers providers to refuse to work in ART clinics:

In 2005 [...] I was directly involved with the ART Department. Now [after 2010] there was unfairness in the working hours. I was told to be working long hours[8 hour] shifts in the ART department-with no incentive. So I tabled it with the sister in-charge and got a departmental transfer, [although] I was one of the three people who opened the ART centre so it was hard for them. OPD Nurse, HC1

Such actions created ad hoc crises for HIV service delivery as previously well-staffed ART clinics suffered critical shortages. Concurrently, health workers were

\footnotetext{
${ }^{i i}$ Of note, the response in Health Centre 2, where overtime payments had never been introduced and where a sole provider had received training to deliver HIV services, was somewhat different. Here, the nurse responsible expressed enthusiasm and dedication to her HIV duties and frustration that she was expected to handle 'additional' OPD patients.

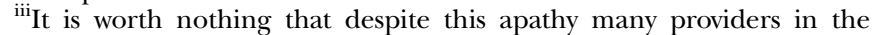
three urban health centres continued to articulate the needs of HIV patients as 'special' or somehow different from those of non-HIV patients, suggesting that a deep-rooted though often unacknowledged form of exceptionalism may have continued to influence their attitudes towards HIV service-delivery.
}

beginning to grasp the implications of life-time care for an ever-expanding patient-load, and feeling increasingly exposed by what they saw as lack of government support to deliver services to exponentially increasing numbers of HIV clients. In the quote below, a nurse reflected on the need to distinguish her own role and responsibilities from that of the 'the government' who she blamed for chronic health worker and other resource shortages that continually undermined her performance:

Patients cannot understand. They start shouting as if you are the Minister [for Health]. They regard you as part of the government. But I am just a civil servant! What can I do if I get no support? Nurse, HC3.

\section{Trust in supervisor}

In previous work examining trust in Zambian health centres, ${ }^{35}$ it was demonstrated that three major factors contributed to generally weak trust in health centre managers, respectively: perceptions of favouritism; experiences with poor communication and information dissemination and finally weak problem-solving capacity.

Data from the current study demonstrate that during the HIV service establishment phase, the emphasis of stand-alone ('vertical') HIV service delivery exacerbated health workers' perceptions of favouritism among their supervisors due largely to the phased and selective nature ART training (in-service) opportunities. Access to the limited training places were highly sought after as they represented a rare opportunity for professional development as well as ensuring eligibility to work in the ART clinics where overtime shifts were paid. Selection was by nomination from the overall health centre manager and confirmation of the responsible District official. But various health workers described these decisions as nontransparent and viewed supervisors' choices with suspicion:

You know some seem to be "higher" [in the eyes] of the in-charge. It would be best to give each and every person [a chance] to say [whether] they can you do this. Not where [she] picks on you today, "go and attend this ART workshop", and again another day: "go and attend to this other [workshop]." What about other people? So again that is demoralising. OPD Nurse, HC1

Consequences of this distrust in the equitable nature of supervisors' decisions were varied. In several cases, managers described staff calling in sick, finding excuses not to come to work or refusing to help cover shifts when the ART clinic was short-staffed.

On the trainings it proved to be problematic [...] when there is a shortage in that department, nurses would say: "I'm not trained" and refuse to cover. Then patients end up suffering. Former ART Manager.

Yes, we have a lot of challenges. [...] We find the situation where someone is favoured to go for ART workshops, the other one is not favoured. So you find the 
next week that person [who wasn't selected] will just tell you, "I'm not feeling fine" or "I don't have transport money, I can't come." They want everything to go equally and when it doesn't [they are] difficult. ART/OPD Manager, HC4.

Perceptions of inequity and lack of trust in the transparency with which supervisors made such choices undermined morale, motivation and commitment to the job as discussed further in the next section.

\section{Trust in colleagues}

An initial strengthening of trust appeared to take place among providers who worked together in ART clinics during the establishment phase. In-service training opportunities, the provision of financial incentives, recruitment of auxiliary health workers and quality assurance and more consistent supervision contributed to high degrees of intrinsic and extrinsic motivation and a virtuous and team-oriented work culture. In the quote below one nurse reflected on the fact that in the ART clinic she was able to carry out mandated tasks as part of functional team instead of multitasking and 'stopgapping' as was required in other departments:

'[In ART] I am doing proper nursing, where I'm doing what I am supposed to be doing and others were also are doing what they should. Not like in OPD where I have to do everything. ART Nurse, HC3.

Notwithstanding this positive impact, two other, largely negative effects were identified. First, findings from three clinics (HC1, 3, 4) demonstrated that while trust in colleagues was strengthened within ART clinics, trust in colleagues across the facilities as a whole was weakened. Provider interviews and observations highlighted divisive 'us and them' attitudes between personnel from the ART clinic and other departments, as uneven investment in material resources, training opportunities, financial incentives and clinical support fuelled resentment and suspicion:

There was tension with the people working in ART and people working [elsewhere]. In ART they used to get paid, so it means the people who were working that side used to have two salaries compared to the ones [in other departments]. So there used to be confusion, all people wanted to go to ART [...] where there was money. OPD Registry Clerk, HC1

I'd say the staff relations changed because the staff who were working in departments where they didn't have resources would feel like ART was superior, and that the people who are working there were more comfortable. They felt we had everything that they want to use and they would regard that department as rich, much richer than the other departments. Former ART Manager

R: So when ART was introduced [as a] separate entity [...] most people were saying it was for the few people working in that department. It had an impact on the other members of staff especially those who were not involved.

I: What sort of impact?

R: They felt isolated [..] initially it started with one-on-one talking, issues like: "It's you who went for a training, so you can do it that way. I haven't gone for a training so I don't have to." Overall Manager, HC4

Weakened interdepartmental trust and heightened resentments among colleagues weakened continuity of care, with respondents reporting that, initially at least, some staff refused to deal with HIV patients who presented in other departments because that was 'the job of those working in the other department' [Nurse, HC1].

Especially when trainings started, those who didn't go, they felt left out [...] So initially that brought in a little bit of a problem. That tension between people [who] were now saying: "As long as you are an HIV patient, [we] will not want to attend to you; those [working at ART] can attend to you." Overall Manager, HC4.

Interview data and in-person observations did suggest, however, that by late 2011, with the removal of overtime payments, the increased number of staff accessing ART training and the integration of HIV and routine outpatient services in some facilities, inter-departmental tensions had waned to some degree as the providers adjusted to the new arrangements.

\section{IMPACT OF HIV SERVICE SCALE-UP ON PATIENT- PROVIDER TRUST \\ Interpersonal trust}

The initial investment in HIV services during the establishment phase had an overall positive impact of interpersonal trust between and HIV patients and ART clinic staff. Patients and providers reported that during the first years of HIV service scale-up providers delivered high quality and more personalised care by comparison to other health centre departments:

For HIV patients things were done properly. It's not just that there was competence. There was care. These things were not there in OPD. Clinician, HC4.

Reflecting on their early experiences in the ART clinics, HIV patients too frequently expressed sentiments of trust in the quality of care based on repeatedly positive experiences of interpersonal interactions as well as resource availability:

The medication is always there. The counselling is good. The treatment is good. Especially the counsellor in adherence always makes me feel good because they try to hear my side of the story. ART Patient, Female, HC1

Over time, however, patients' interpersonal trust in ART clinic providers appeared to wane. Although not 
universal (positive accounts of ART clinic health workers were gathered) negative accounts of interpersonal interaction were more frequent within individual narratives and across the data set as a whole when patients reflected on their recent experiences in ART clinics. Recurring themes related to interpersonal trust gathered from interview data included patients' perceptions of workers' inefficiency, laxity and experiences of verbal abuse, with in-person observation confirming such behaviour. Indeed, as summarised in table 3 , narratives indicative of weak interpersonal trust were common among patients in all health centre departments suggesting that the higher levels of trust expressed in ART clinic providers during the establishment phase were exceptional and that in the long-term, weak interpersonal trust was the norm.

\section{Institutional trust}

Although providers received additional training prior to participating in HIV service delivery, this was not widely recognised by patients. Just as in the outpatient departments, for example, HIV patients expressed a preference for consultation with a doctor, but rarely specified that the doctor should have specific training or experience; trust in the technical capabilities of health professionals was already strong.

We all trust the doctor. The doctor knows more about illness. [HIV Patient, HC3]

However patients' institutional trust was positively impacted in another way; by the almost universal recognition that the benefits of 'free and lifesaving' HIV services afforded HIV-positive individuals. In all four health centres, HIV and non-HIV patients described guaranteed provision of free HIV medications as an important development in Zambian public health services, voicing appreciation of this new service even when they themselves were not accessing it:

It is positive that people are able to access ARVs, which has reduced the death rate. People are able to come and know their status. And counselling is provided at any time. HIV Patient, HC1

People are happy about the drugs; they receive free treatment and drugs; those who are HIV positive they don't pay for some health treatment. MCH Patient, HC4

Patients also frequently commented on the more secure availability of ARV drugs, particularly by comparison to other departments:

I would like the donors and the government to increase the drugs at the outpatient department. Just the way they have increased the ARVs. You know that ARVs are always there. But with the other [departments], they run out. MCH Patient, HC4

Such comments implied a heightened degree of institutional and health system trust among patients arising from the initial investment and scaled-up access to HIV services that remained strong (and did not wane) over time.

\section{DISCUSSION}

This study set out to explore whether, and in what ways, the rapid establishment and scale-up of HIV services influenced trust in four Zambian health centres. Complementing a body of existing empirical work that has historically focused on the impact of HIV service scale-up on health system hardware, ${ }^{23} 26$ this study provides new insights into the impact of HIV scale-up on critical relational (or software) aspects of the health system. To the best of our knowledge, it is the first study to examine the impact of a disease-specific programming (HIV or otherwise) on the production of trust at any level in a low-income or middle-income setting. The highly localised nature of this work and use of methods designed to allow a 'deep dive' into the organisational and relational culture are a strength of the study, supporting broader, analytic generalisability.

Our findings demonstrate that the way HIV service scale-up was implemented in the four sites had positive and negative impacts on the production of trust. During the establishment phase, investment in HIV-specific infrastructure, health information systems and supplies (hardware) as well as quality assurance and supportive supervision (software) promoted workplace trust and patient-provider trust in the ART clinics via positive feedback loops-as outlined in figure 2A. Improved resourcing and support for ART clinic services bolstered health workers' confidence in the type and consistency of organisational support they were likely to receive (albeit focused on NGO partners) ${ }^{52-54}$ which in turn strengthened extrinsic and intrinsic motivation ${ }^{55}$ and provider performance. Provider performance, materially and relationally, acted as a key determinant of the comparatively higher levels of patient-provider trust found in ART clinics during this early phase. Such findings mirror Tendler's ${ }^{56}$ observation that mutually trusting relationships are more likely to evolve in an enabling environment, and a rich body of literature describing the relationship between trust, perceptions of organisational support and workplace motivation. ${ }^{57}$

Notwithstanding these short-term positive outcomes, our findings demonstrate few if any positive impacts on the production of trust in the wider health centres, and a potentially damaging intensification of workplace distrust (specifically distrust in the $\mathrm{MOH}$ and government) in the long term. Findings demonstrate, for example, that the NGO-led investment and support for ART clinics during the establishment phase reinforced many health workers' existing perceptions of the government as either uninterested or unable to support a conducive work environment. Findings also demonstrated that the uneven distribution of professional opportunities associated with HIV scale-up (eg, in-service training and overtime payments) exacerbated perceptions of systemic workplace inequity and nepotism, contributing to 
Table 3 Illustrative quotes demonstrating patients' perceptions of health workers in different departments in four study sites

\begin{tabular}{|c|c|c|c|c|}
\hline & HC1 & $\mathrm{HC2}$ & HC3 & HC4 \\
\hline ART clinic & $\begin{array}{l}\text { The nurses should be kind. They } \\
\text { should know that they are dealing } \\
\text { with people who are sick. If they feel } \\
\text { that there is the work load they } \\
\text { should be frustrated with the } \\
\text { government not to us. [Female, HIV] } \\
\text { Sometimes [the health workers] } \\
\text { forget they are at the institution } \\
\text { where they are dealing with sick } \\
\text { people. Sometimes they don't care if } \\
\text { you are very sick or not. They are } \\
\text { just very slow in working. [Male, HIV] }\end{array}$ & $\begin{array}{l}\text { The clinic should have time to } \\
\text { people who are on ARVs and they } \\
\text { should pay more time and ask them } \\
\text { what problems they face. [Female, } \\
\text { HIV] } \\
\text { Yes, the number of health workers } \\
\text { should increase because you find } \\
\text { that we stay at the clinic without } \\
\text { being attended to all because there } \\
\text { are few health workers. [Male, HIV] }\end{array}$ & $\begin{array}{l}\text { This clinic is fine but the ART } \\
\text { department the health workers are } \\
\text { very slow. [Male, HIV] } \\
\text { The health workers at this clinic are } \\
\text { very lazy and very relaxed. They take } \\
\text { up too much of their time before } \\
\text { attending to us especially the clinical } \\
\text { officers. [Male, HIV] }\end{array}$ & $\begin{array}{l}\text { In my experience, nurses should be } \\
\text { nicer with the patients, not shouting } \\
\text { at us. And they should teach these } \\
\text { clerks how to handle files so they } \\
\text { don't get lost. [Female, HIV] } \\
\text { At this clinic, ART files keep going } \\
\text { missing and they will open another } \\
\text { one for you but you find that you } \\
\text { lose out on the way you used to } \\
\text { take your drugs or your health } \\
\text { record. [Male, HIV] }\end{array}$ \\
\hline $\begin{array}{l}\text { Maternal and } \\
\text { child health } \\
\text { department }\end{array}$ & $\begin{array}{l}\text { My experiences are that most of the } \\
\text { time the } \mathrm{CO} \text { and nurses spend most } \\
\text { of their time discussing unnecessary } \\
\text { stories. They even go for lunch early. } \\
\text { [Female, } \mathrm{MCH} \text { ] } \\
\text { This clinic works well but we need } \\
\text { more medication. Prescriptions don't } \\
\text { help especially when you don't have } \\
\text { money. [Female, MCH] }\end{array}$ & $\begin{array}{l}\text { This clinic they don't take patients to } \\
\text { be important. So you find that they } \\
\text { shout at us sometimes even when } \\
\text { we are right. [Female, } \mathrm{MCH} \text { ] } \\
\text { It is very discouraging coming to this } \\
\text { clinic because sometimes they are } \\
\text { very slow to attend to patients. And } \\
\text { they are not even bothered if we are } \\
\text { happy about it or not. [Female, } \mathrm{MCH} \text { ] }\end{array}$ & $\begin{array}{l}\text { Nurses work very well but sometimes } \\
\text { they are slow. [Female, MCH] } \\
\text { They should improve on how they } \\
\text { give the drugs because most of the } \\
\text { time they just give prescriptions. For } \\
\text { us to go and buy medicine instead } \\
\text { they get the medicine who knows } \\
\text { where they take it! [Female, } \mathrm{MCH} \text { ] }\end{array}$ & $\begin{array}{l}\text { When you come for family planning } \\
\text { they tell you to buy the drugs for } \\
\text { injection. That is very bad and } \\
\text { instead of telling us in a polite way } \\
\text { they shout at you. [Female, } \mathrm{MCH} \text { ] } \\
\text { Nurses at } \mathrm{MCH}[\ldots] \text { sometimes } \\
\text { shout at patients. We take it as a } \\
\text { normal thing because they are used } \\
\text { to shouting at us. Maybe it is their } \\
\text { way of not wanting us to ask many } \\
\text { questions. [Female, MCH] }\end{array}$ \\
\hline $\begin{array}{l}\text { Outpatient } \\
\text { Department }\end{array}$ & $\begin{array}{l}\text { Health workers should be serious, } \\
\text { not like nurses [now] they are just } \\
\text { chatting here. [Female, OPD] } \\
\text { Please they should stop having a lot } \\
\text { of stories instead of working } \\
\text { especially today when there is these } \\
\text { new nurses. [Male, OPD] }\end{array}$ & $\begin{array}{l}\text { Time, they always start very late as I } \\
\text { have told you, we reach here mostly } \\
\text { at } 6 \text { hrs and they start attending to } \\
\text { you around } 9 \text { hrs. [Female, OPD] } \\
\text { People work very slow here at the } \\
\text { clinic. You can find someone maybe } \\
\text { a nurse just moving about, forgetting } \\
\text { that patients are waiting. [Male, OPD] }\end{array}$ & $\begin{array}{l}\text { The members of staff should stop } \\
\text { getting money from patients to collect } \\
\text { their drugs. If you don't have money } \\
\text { here then you go home very late } \\
\text { [Female, OPD] } \\
\text { There are a lot of health workers } \\
\text { they should stop chatting when it is } \\
\text { the time for them to work. They } \\
\text { should concentrate on the patients } \\
\text { first instead of gossiping. [Female, } \\
\text { OPD] }\end{array}$ & $\begin{array}{l}\text { The problem is with the nurses who } \\
\text { are very harsh with patients. } \\
\text { Sometimes they shout at some } \\
\text { patients [Male, OPD] } \\
\text { The health workers most of them } \\
\text { come late (doctor) and take time } \\
\text { before attending to patients, this } \\
\text { angers some of the patients and } \\
\text { they start shouting at the health } \\
\text { workers. [Female, OPD] }\end{array}$ \\
\hline
\end{tabular}

$\mathrm{ART}$, antiretroviral therapy clinic; $\mathrm{MCH}$, maternal and child health department; OPD, outpatient department. 
A

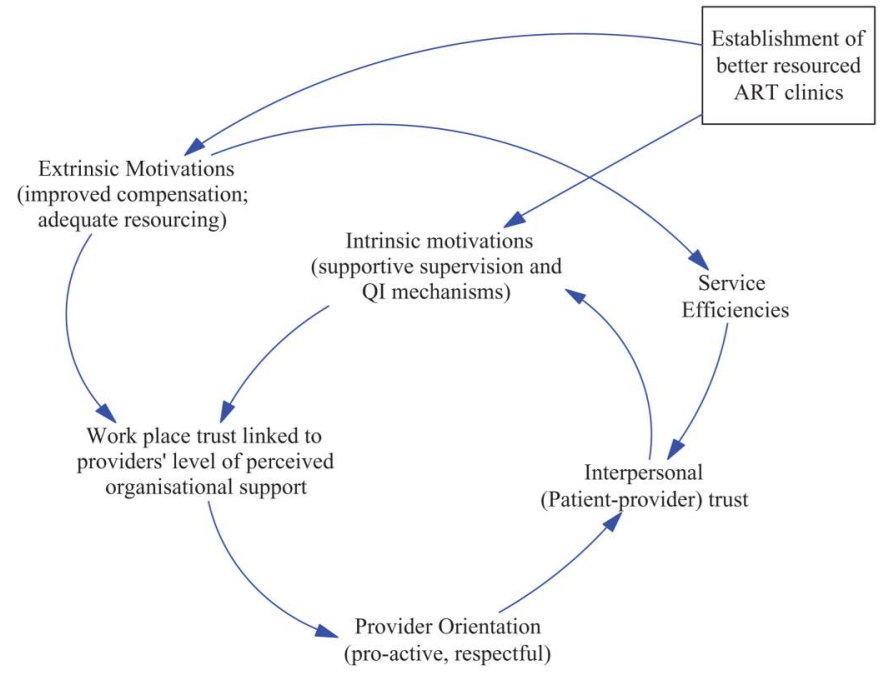

\section{ART Clinic}

B

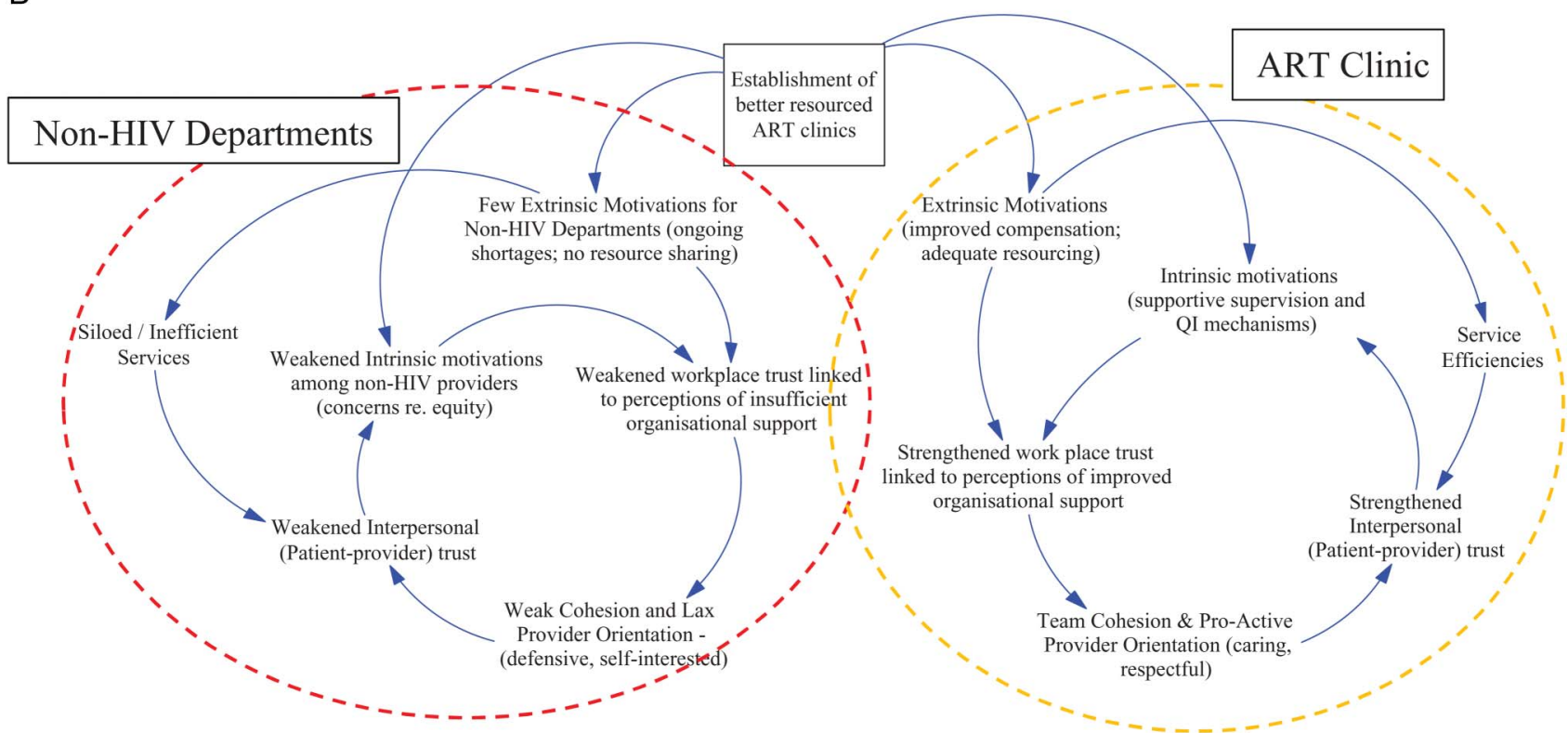

Figure 2 Impact of establishment phase on trust in (A) the ART clinic and (B) broader health centre. ART, antiretroviral therapy clinic.

interdepartmental antagonism and reinforcing existing negative workplace practices such as absenteeism and deliberate siloing of service activities to minimise workload. $^{35}$

Existing distrust in the government was such that, when oversight for the ART clinics transitioned from NGO partners to $\mathrm{MOH}$, many if not most providers viewed the decline in supportive supervision and removal of overtime payments as confirmation of their impression that the government was neither competent to, nor interested in, looking after its workforce. The outcome, as captured in figure 3, was an observed (albeit unquantified) deterioration in ART clinic performance underpinned by a re-emergence of work practices long established in the broader health centres. ${ }^{55}$
An explicit question posed by this research was whether investment in HIV service scale-up strengthened relational aspects of the health system and with what implications for service quality and responsiveness. What the findings suggest is that the structure of investment in HIV service scale-up in Zambia failed to engage with the complexity of the relational aspects of the health centre microsystems. Perhaps influenced by programme theories that assume front-line health services are simple, mechanistic systems, interventions such as those financed through global health initiatives are often based on the logic of linear causal pathways. ${ }^{59-61}$ This logic assumes investment in one area of the system will automatically produce positive effects overall. ${ }^{62}$ Certainly in the four health centres in this study, ART 


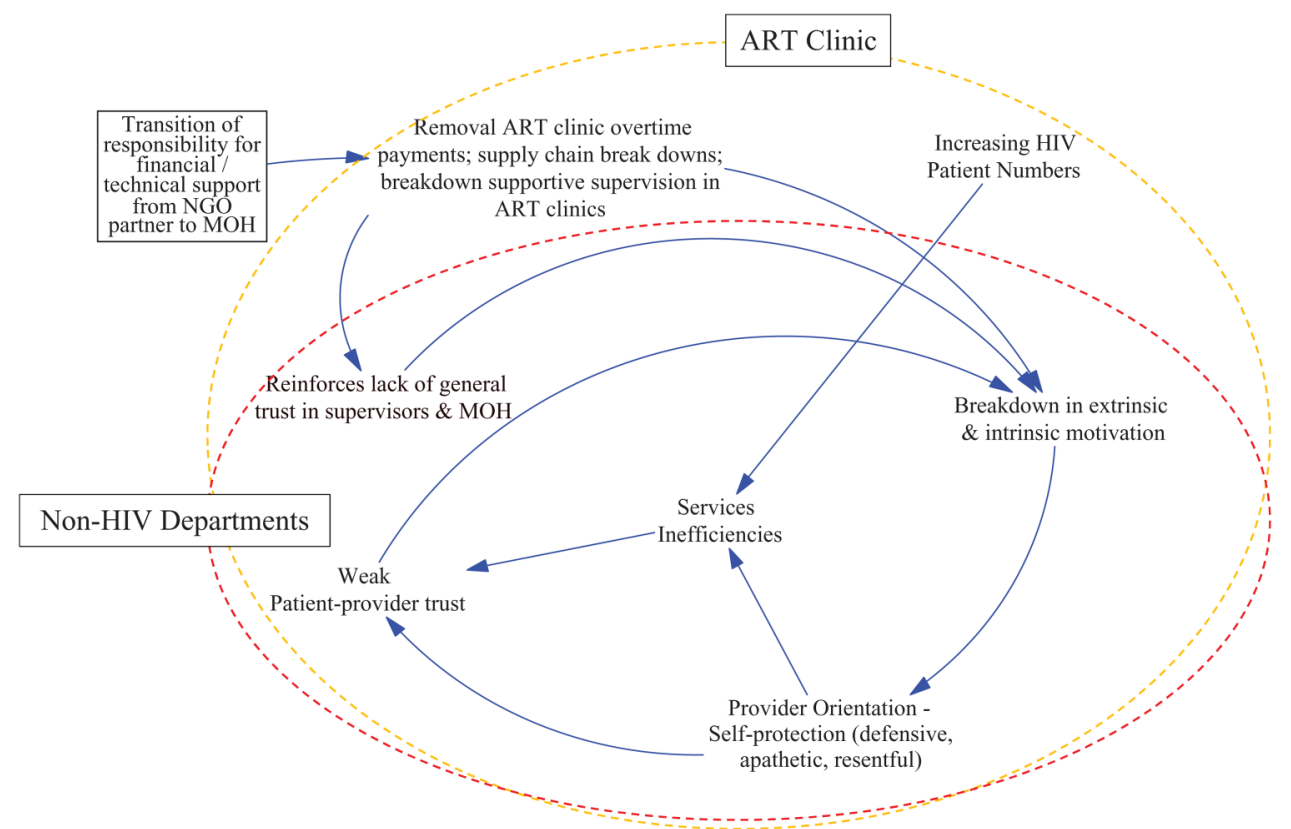

Figure 3 Impact of transition phase on trust in ART clinic and broader health centre. ART, antiretroviral therapy clinic; MOH, Ministry of Health; NGO, non-governmental organisation.

clinics were described by key informants as essentially stand-alone entities and with scale-up activities focused exclusively on HIV-related services there was little consideration for the way these would impactmaterially or relationally-on the broader health centre 'eco-system'.

The urgent need to strengthen workplace and patientprovider relationships that underpin viable and responsive health systems in Zambia and other low and middle-income countries (LMIC) is evident in a growing body of work documenting the damaging and often cyclical consequences of weak workplace motivation, poor health worker retention and abusive patient-provider interactions. ${ }^{63-67}$ Indeed the role of (weak) community confidence and (lack of) trust in public primary health services has most recently been recognised as a critical determinant of (insufficiently) resilient health systems in the context of public health emergencies such as the recent Ebola epidemic. ${ }^{68}{ }^{69}$ In this respect, the finding that HIV scale-up did little to disrupt and potentially even exacerbated providers' distrust in their government employer, regular supervisors and long-term colleagues takes on new significance. At best it suggests that the watershed investment in $\mathrm{HIV}$-specific services from the mid-2000s represents a 'lost opportunity' to strengthen workplace trust that (beyond the obvious and short-term impact of new resourcing) could have positively and sustainably influenced the quality and responsiveness of all primary-level services, including those of the ART clinics.

\section{CONCLUSIONS}

Research presented in this paper adds to a small but important body of work that provides empirical evidence of the way targeted interventions have multiple, intended and unintended effects on system performance. The study illustrates the positive short-term and less positive long-term effects of HIV-specific investment on workplace trust demonstrating how despite some initial gains in service quality and responsiveness, sustained improvements were ultimately inhibited by the disease-specific nature of the intervention. These findings point to the importance of global, national and subnational policymakers' and implementers, recognising the central place that human relationships play in generating virtuous and perverse service cycles. Better understanding the interaction between such disease-specific interventions and the human systems in which they are located, including their impact on social institutions such as trusting relationships, will be critical to ensuring any similar future initiatives achieve genuine or sustained system strengthening effects.

\section{Handling editor Valery Ridde.}

Twitter Follow Stephanie Topp @globalstopp

Contributors SMT designed the study, collected data led analysis and wrote the first draft of the manuscript. JMC contributed to data collection and analysis and provided critical edits.

Competing interests None declared.

Ethics approval Nossal Institute for Global Health Human Research Ethics Committee; University of Zambia Biomedical Research Ethics Committee.

Provenance and peer review Not commissioned; externally peer reviewed.

Data sharing statement No additional data are available.

Open Access This is an Open Access article distributed in accordance with the Creative Commons Attribution Non Commercial (CC BY-NC 4.0) license, which permits others to distribute, remix, adapt, build upon this work noncommercially, and license their derivative works on different terms, provided 
the original work is properly cited and the use is non-commercial. See: http:// creativecommons.org/licenses/by-nc/4.0/

\section{REFERENCES}

1. Rabkin M, El-Sadr WM, De Cock KM. The impact of HIV scale-up on health systems: a priority research agenda. J Acquir Immune Defic Syndr 2009;52(Suppl 1):S6-11.

2. UNAIDS. How AIDS changed everything. Geneva: UNAIDS, 2015. http://www.unaids.org/sites/default/files/media_asset/MDG6Report_ en.pdf

3. Levine R, Oomman N. Global HIV/AIDS funding and health systems: searching for the win-win. J Acquir Immune Defic Syndr 2009;52 (Suppl 1):S3-5.

4. Banteyerga $\mathrm{H}$, Kidanu $\mathrm{A}$, Stillman $\mathrm{K}$. The systemwide effects of the Global Fund in Ethiopia: Final Study Report. 2006, Bethesda, MD: Abt Associates Inc.

5. Bloom G, Standing $\mathrm{H}$. Future health systems: why future? why now? Soc Sci Med 2008:66:2067-75.

6. Eisenhut M, Sharma, Kawsar M, et al. Knowledge of their children's HIV status in HIV-positive mothers attending a genitourinary medicine clinic in the UK. HIV Med 2008:9:257-9.

7. England R. The dangers of disease specific aid programmes. BMJ 2007;335:565.

8. England R. The writing is on the wall for UNAIDS. BMJ 2008;336:1072

9. Haines A. Editorial: contribution of health systems to disease control. Trop Med Int Health 2007;12:1275-8.

10. Harries AD, Zachariah R, Tayler-Smith $\mathrm{K}$, et al. Keeping health facilities safe: one way of strengthening the interaction between disease-specific programmes and health systems. Trop Med Int Health 2010;15:1407-12.

11. Mtonya B, Chizimbi S. The systemwide effects of the Global Fund in Malawi: final study report. Geneva: The Global Fund to fight AIDS, Tuberculosis and Malaria, 2006.

12. Biesma R, Makoa E, Mpemi R, et al. The implementation of a global fund grant in Lesotho: applying a framework on knowledge absorptive capacity. Soc Sci Med 2012;74:381-9.

13. Cohn J, Russell A, Baker BK, et al. Using global health initiatives to strengthen health systems: a civil society perspective. Glob Public Health 2010;6:687-702.

14. Hanefeld J. The impact of Global Health Initiatives at national and sub-national level-a policy analysis of their role in implementation processes of antiretroviral treatment (ART) roll-out in Zambia and South Africa. AIDS Care 2010;22(Suppl 1):93-102.

15. Hanefeld J, Musheke M. What impact do Global Health Initiatives have on human resources for antiretroviral treatment roll-out? A qualitative policy analysis of implementation processes in Zambia. Hum Resour Health 2009;7:8.

16. Spicer N, Aleshkina J, Biesma R, et al. National and subnational HIV/AIDS coordination: are global health initiatives closing the gap between intent and practice? Global Health 2010;6:3.

17. De Cock KM, El-Sadr WM, Ghebreyesus TA. Game changers: why did the scale-up of HIV treatment work despite weak health systems? J Acquir Immune Defic Syndr 2011;57(Suppl 2):S61-3.

18. Grepin KA. HIV donor funding has both boosted and curbed the delivery of different non-HIV health services in sub-Saharan Africa. Health Aff (Millwood) 2012;31:1406-14.

19. Kruk ME, Jakubowski $A$, Rabkin $M$, et al. PEPFAR programs linked to more deliveries in health facilities by African women who are not infected with HIV. Health Aff (Millwood) 2012;31:1478-88.

20. Institute of Medicine, Evaluation of PEPFAR. Chapter 9. Committee on the Outcome and Impact Evaluation of Global HIV/AIDS programs implemented under the Lantos-Hyde Act of 2008. Washington (DC): Institute of Medicine, 2013.

21. Riley PL, Vindigni SM, Arudo J, et al. Developing a nursing database system in Kenya. Health Serv Res 2007:42(3 Pt 2):1389-405.

22. Oomman N, Bernstein M, Rosenzweig S. Following the funding for HIVIAIDS: a comparative analysis for the funding practices of PEPFAR, the Global Fund and the World Bank MAP in Mozambique, Uganda, and Zambia. Washington (DC): Center for Global Development, 2007.

23. Luboga SA, Stover B, Lim TW, et al. Did PEPFAR investments result in health system strengthening? A retrospective longitudinal study measuring non-HIV health service utilization at the district level. Health Policy Plan 2016;31:897-909.

24. Shiffman J. Has donor prioritization of HIV/AIDS displaced aid for other health issues?. Health Policy Plan 2008;23:95-100.
25. Biesma RG, Brugha R, Harmer A, et al. The effects of global health initiatives on country health systems: a review of the evidence from HIV/AIDS control. Health Policy Plan 2009;24:239-52.

26. Marchal B, Cavalli A, Kegels G. Global health actors claim to support health system strengthening: is this reality or rhetoric?. PLOS Med 2009;6:e1000059.

27. Bajunirwe $\mathrm{F}$, Twesigye $\mathrm{L}$, Zhang $\mathrm{M}$, et al. Influence of the US President's Emergency Plan for AIDS Relief (PEPfAR) on career choices and emigration of health-profession graduates from a Ugandan medical school: a cross-sectional study. BMJ Open 2013;3:e002875.

28. Samb B, Evans T, Dybul M, et al., World Health Organization Maximizing Positive Synergies Collaborative Group. An assessment of interactions between global health initiatives and country health systems. Lancet 2009;373:2137-69.

29. Brugha R, Simbaya J, Walsh A, et al. How HIV/AIDS scale-up has impacted on non- HIV priority services in Zambia. BMC Public Health 2010;10:540.

30. Schneider H, Blaauw D, Gilson L, et al. Health systems and access to antiretroviral drugs for HIV in Southern Africa: service delivery and human resources challenges. Reprod Health Matters 2006;14:12-23.

31. Schneider H, Gilson L, Ogden J, et al. Health systems and the implementation of disease programmes: case studies from South Africa. Glob Public Health 2006;1:49-64.

32. Schneider $\mathrm{H}$, Hlophe $\mathrm{H}$, Van Rensburg D. Community health workers and the response to HIV/AIDS in South Africa: tensions and prospects. Health Policy Plan 2008;23:179-87.

33. Schneider $\mathrm{H}$, Lehmann U. Lay health workers and HIV programmes: implications for health systems. AIDS Care 2010;22(Suppl 1):60-7.

34. Freedman L. Achieving the MDGs: health systems as core social institutions. Development 2005;48:19-24.

35. Topp SM, Chipukuma JM. A qualitative study of the role of workplace and interpersonal trust in shaping service quality and responsiveness in Zambian primary health centres. Health Policy Plan 2016;31:192-204.

36. Topp SM, Chipukuma JM, Hanefeld J. Understanding the dynamic interactions driving Zambian health centre performance: a case-based health systems analysis. Health Policy Plan 2015;30:485-99.

37. Hall MA, Dugan E, Zheng B, et al. Trust in physicians and medical institutions: what is it, can it be measured, and does it matter? Milbank Q 2001;79:613.

38. Gilson L. Trust in health care: theoretical perspectives and research needs. J Health Organ Manag 2006;20:359-75.

39. Goold SD. Trust and the ethics of health care institutions. Hastings Cent Rep 2001;32:26-33.

40. Lewicki RJ, Bunker BB. Trust in relationships: a model of development and decline. In: Bunker BB, Jeffry Z, eds. Conflict, Cooperation and justice. San Francisco (CA): Jossey-Bass Publishers, 1996. p.133-173.

41. Mcknight DH, Chervany NL. The meanings of trust, in Meeting of the Academy of Management. 1996. Technical Report, University of Minnesota, http://www.misrc.umn.edu/workingpapers/fullpapers/ 1996/9604_040100.pdf; accessed 11 Nov. 2016.

42. Nyhan RC. Changing the paradigm - trust and its role in public sector organizations. Am Rev Public Adm 2000;30:87-109.

43. Wuthnow R. Trust as an aspect of social structure. In: Alexander JC, Marx CT, Williams CL, eds. Self, Social Structure and Beliefs: explorations in sociology. Berkeley (CA): University of California Press, 2004:146.

44. $\mathrm{MOH}$ and GRZ. Zambia Health Facility Census Analytical Report. Ministry of Health, Government of the Republic of Zambia Lusaka, 2007

45. Yin RK. Case study research: design and methods. 4th edn. Applied social research methods series. London: Sage, 2009.

46. Topp SM, Chipukuma JM, Chiko MM, et al. Integrating HIV treatment with primary care outpatient services: opportunities and challenges from a scaled-up model in Zambia. Health Policy Plan 2013;28:347-57.

47. Topp SM, Chipukuma JM, Giganti M, et al. Strengthening health systems at facility-level: feasibility of integrating antiretroviral therapy into primary health care services in Lusaka, Zambia. PLoS One 2010;5.

48. Krumpal I. Determinants of social desirability bias in sensitive surveys: a literature review. Qual Quant 2013;47:2025-47.

49. CSO and GRZ. Zambia: 2010 Census of Population and Housing: population summary report. Central Statistical Office, Government of the Republic of Zambia Lusaka, 2012.

50. Masumbu G. Comparison of welfare status of districts in Zambia. Lusaka, Zambia: Zambia Institute for Policy Analysis and Research, ZIPAR, 2014. 
51. Chee G, Pielemeier N, Lion A, et al. Why differentiating between health system support and health system strengthening is needed. Int J Health Plann Manage 2013;28:85-94.

52. Chen ZX, Eisenberger $\mathrm{R}$. The mediate effect of multidimensional perceived organizational support in the relationship of supportive human resource practices and Chinese employees' job performance. Int J Psychol 2008;43:616.

53. Eder P, Eisenberger R. Perceived organizational support: reducing the negative influence of coworker withdrawal behavior. J Manag 2008;34:55-68.

54. Kim KY, Eisenberger R, Baik K. Perceived organizational support and affective organizational commitment: moderating influence of perceived organizational competence. J Organ Behav 2016;37:558-83.

55. Franco LM, Bennett S, Kanfer R, et al. Determinants and consequences of health worker motivation in hospitals in Jordan and Georgia. Soc Sci Med 2004;58:343-55.

56. Tendler J. Good government in the tropics. Baltimore (MD): The Johns Hopkins Press, 1997.

57. Okello DR, Gilson L. Exploring the influence of trust relationships on motivation in the health sector: a systematic review. Hum Resour Health 2015;13:16.

58. Goudge J, Gilson L. How can trust be investigated? Drawing lessons from past experience. Soc Sci Med 2005;61:1439-51.

59. Bennett S, Agyepong IA, Sheikh K, et al. Building the field of health policy and systems research: an agenda for action. PLOS Med 2011;8:e1001081.

60. Gilson L, Hanson K, Sheikh K, et al. Building the field of health policy and systems research: social science matters. PLoS Med 2011;8:e1001079.
61. Sheikh K, Gilson L, Agyepong IA, et al. Building the field of health policy and systems research: framing the questions. PLoS Med 2011;8:e1001073.

62. Topp SM, Black J, Morrow M, et al. The impact of human immunodeficiency virus (HIV) service scale-up on mechanisms of accountability in Zambian primary health centres: a case-based health systems analysis. BMC Health Serv Res 2015;15:67.

63. Kujawski S, Mbaruku G, Freedman LP, et al. Association between disrespect and abuse during childbirth and women's confidence in health facilities in Tanzania. Matern Child Health $J$ 2015;19:2243-50.

64. Abuya T, Warren CE, Miller N, et al. Exploring the prevalence of disrespect and abuse during childbirth in Kenya. PLoS One 2015;10:e0123606.

65. Freedman LP, Ramsey K, Abuya T, et al. Defining disrespect and abuse of women in childbirth: a research, policy and rights agenda. Bull World Health Organ 2014;92:915-17.

66. Okafor II, Ugwu EO, Obi SN. Disrespect and abuse during facility-based childbirth in a low-income country. Int $J$ Gynaecol Obstet 2015;128:110-13.

67. Sando D, Kendall T, Lyatuu G, et al. Disrespect and abuse during childbirth in Tanzania: are women living with HIV more vulnerable? J Acquir Immune Defic Syndr 2014;67(Suppl 4):S228-34

68. Agyepong IA. A systems view and lessons from the ongoing Ebola Virus Disease (EVD) outbreak in West Africa. Ghana Med J 2014:48:168-72.

69. Thiam S, Mansour Niang M, Gueye L, et al. Challenges in controlling the Ebola outbreak in two prefectures in Guinea: why did communities continue to resist? Pan Afr Med J 2015;22(Suppl 1):22. 